\title{
Surveillance for outbreaks of gastroenteritis in elderly long-term care facilities in France, November 2010 to May 2012
}

A S Barret (as.barret@invs.sante.fr) ${ }^{1}$, N Jourdan-da Silva ${ }^{1}$, K Ambert-Balay $^{2}$, G Delmas ${ }^{1}$, A Bone $^{1,3}$, J M Thiolet $^{1}$, V Vaillant $^{1}$

1. Institut de Veille Sanitaire, Saint-Maurice, France

2. Centre national de référence des virus entériques, Dijon, France

3. European Programme for Intervention Epidemiology Training (EPIET), European Centre for Disease Prevention and Control $(E C D C)$, Stockholm, Sweden

Citation style for this article:

Barret AS, Jourdan-da Silva N, Ambert-Balay K, Delmas G, Bone A, Thiolet JM, Vaillant V. Surveillance for outbreaks of gastroenteritis in elderly long-term care facilities in France, November 2010 to May 2012 . Euro Surveill. 2014;19(29):pii=20859. Available online: http://www.eurosurveillance.org/ViewArticle. aspx?Articleld $=20859$

Article submitted on 18 March 2013 / published on 25 July 2014

This article describes outbreaks of gastroenteritis in elderly long-term care facilities (LTCF) in France from November 2010 to May 2012 reported through the surveillance system for gastroenteritis outbreaks in LTCF. A total of 1,072 outbreaks were reported, causing 26,551 episodes of illness and 60 deaths. The median attack rate (AR) among residents was $32 \%$. Norovirus and person-to-person transmission were the most frequently reported aetiology and mode of transmission. Control measures were implemented in 1,054 (98\%) outbreaks and for 928 outbreaks, the timing of such measures could be inferred. Of these, 799 (86\%) had put control measures into effect within three days of the occurrence of the first case. Outbreaks of gastroenteritis in LTCF cause substantial morbidity and mortality among elderly people in France. LTCF are encouraged to develop infection prevention and control plans and to notify any gastroenteritis outbreak to health authorities to ensure rapid control.

\section{Introduction}

Outbreaks of gastroenteritis are frequent in elderly long-term care facilities (LTCF). Because of the increased susceptibility and vulnerability of the residents, they can be associated with significant morbidity and mortality [1-3]. Their detection and control can be challenging. Prompt identification, thorough epidemiological and microbiological investigations, and rapid implementation of control measures are key elements to control outbreaks and limit the impact on the residents and the healthcare service.

In France, elderly LTCF were identified as the most frequent setting for gastroenteritis outbreaks between 2006 and 2009 [4]. In 2010, a specific surveillance system for gastrointestinal outbreaks in elderly LTCF was implemented in mainland France as part of a national plan to reduce the risk of infection in healthcare settings [5]. The objectives of the surveillance system were to promote the early notification of outbreaks, to facilitate the implementation of control measures and to describe the epidemiology of outbreaks in elderly LTCF. This system was implemented in addition to the surveillance systems already in operation for the surveillance of acute gastroenteritis in France [6], which include: (i) the surveillance of acute diarrhoeal disease in the general population by the sentinel network of general practitioners since 1990 [7]; (ii) the syndromic surveillance system based on emergency departments morbidity data (OSCOUR) since 2004 [8]; (iii) the notification of gastroenteritis outbreaks in healthcare settings since 2001; (iv) the mandatory notification of foodborne gastroenteritis outbreaks since 1987; and (v) the confirmation and characterisation of enteric viruses at the National Reference Centre (NRC) of enteric viruses.

The surveillance system for gastrointestinal outbreaks in elderly LTCF was deployed by the regional health agencies in coordination with their partners in the prevention of healthcare-associated infections. In some regions (North, East), a pilot study or a pre-existing enhanced surveillance system had already been implemented prior to 2010.

This article describes the gastroenteritis outbreaks that occurred in elderly LTCF in France between November 2010 and May 2012.

\section{Methods}

Surveillance system for gastroenteritis outbreaks in elderly long-term care facilities The surveillance system for gastroenteritis outbreaks in elderly LTCF has been operating since November 2010. It is based on voluntary notification of any gastroenteritis outbreak occurring in LTCF. Acute gastroenteritis is defined as the sudden onset of diarrhoea (i.e. at least two stools more than usual, soft or watery) within 24 hours or the sudden onset of at least two 
episodes of vomiting within 24 hours, in the absence of a non-infectious aetiology (e.g. use of laxatives or chronic conditions). An outbreak is defined as at least five cases of gastroenteritis within four days among elderly LTCF residents or staff. The coordinator of elderly LTCF informs the health authorities and transmits a standardised notification form by email or fax. Health authorities can advise on the outbreak management, assist in further microbiological and epidemiological investigations and check that appropriate control measures have been implemented. Stool samples are sent to local or hospital laboratories and/or directly to the NRC for enteric viruses. Noroviruses are detected by real-time reverse transcription-polymerase chain reaction (RT-PCR), as previously described $[9,10]$. Rotaviruses, astroviruses, adenoviruses and sapoviruses are detected by RT-PCR as previously described [11].

Surveillance data are then entered by the health authorities in a web-based entry application hosted at the French Institute for Public Health Surveillance. This system enables real-time surveillance and exchange of information.

\section{Data collection and study period}

According to the national recommendations, a notification form should be sent to the health authorities as soon as an outbreak of gastroenteritis is recognised in a facility. The notification form collects the following information:

- Characteristics of the facility: address, type of facility, number of residents, number of staff members, number of units, mean level of dependence in the facility assessed by the French 'autonomie, gérontologie, groupe isoressources' (AGGIR) grid. This grid is used to classify each resident in six levels of dependence, which are then weighted and scored to calculate the mean level of dependence in the facility (for example, the mean level of dependence would be 1,000 if all residents had completely lost their autonomy and needed a continuous support in all their activities); the mean level of dependence in elderly LTCF in France was 575 in 2007 [12,13];

- Aggregated data on outbreaks: date of notification, number of cases among residents, number of cases among staff members, number of deaths and transfers to acute care facilities among residents, date of symptom onset in first and last case, number of affected units, whether the majority of cases ( $\geq 50 \%$ cases) present with diarrhoea, whether the majority of cases ( $250 \%$ cases) present with vomiting, presence of at least one case with fever $\geq 38.5^{\circ} \mathrm{C}$, presence of at least one case with bloody diarrhoea, estimated mean duration of symptoms (in days or hours), laboratory testing performed, suspected or confirmed aetiological agent;

- Outbreak management and control measures: help needed for the implementation of control measures, implementation of an epidemiological investigation (agency in charge of the investigation, type of investigation: descriptive study, review of cases' food consumption, analytical study), suspected mode of transmission, implemented control measures (predefined list: reinforcement of hand hygiene, contact precautions, cleaning or disinfection, etc.), problems in the management of the outbreak (predefined list: understaffing, organisational problems, financial problems, shortage of materials, other),

Gastroenteritis outbreaks that were notified between 01 November 2010 and 31 May 2012 were included in the study. Winter season was defined as the period from 1 November to 31 May.

\section{Descriptive analysis}

Data analysis was conducted using Microsoft Excel 2003 and Stata Version 11. The outbreak notification rate was calculated overall and by region (number of outbreaks reported in the study period divided by the number of elderly LTCF registered in the national administration files [12]). Characteristics of outbreaks and facilities were described as well as investigation and management of outbreaks.

The proportion of affected units was calculated in facilities with at least two units, as the number of affected units divided by the total number of units in the facility reported on the notification form.

The duration of the outbreak was calculated by the difference between the date of symptom onset of the first and last cases. The notification delay was calculated by the difference between the date of symptom onset of the first case and the date of notification to health authorities. The delay in the implementation of control measures was calculated by the difference between the date of symptom onset of the first case and the date of implementation of control measures.

We compared the attack rate (AR) and duration of outbreaks by different characteristics. For categorical variables, rates were compared using Kruskall-Wallis test. For quantitative variables, we computed the Spearman correlation coefficient $r$. For trend analysis, we used the chi-squared test for trend and the nonparametric Cuzick's test for trend.

\section{Results}

Number of outbreaks and characteristics of the reporting facilities

Of 10,205 elderly LTCF recorded in mainland France in $2007,1,040(10 \%)$ facilities reported at least one gastroenteritis outbreak between 1 November 2010 and 31 May 2012, yielding a total of 1,072 gastroenteritis outbreaks in these facilities. Over the study period, 1,013 facilities reported one outbreak, 22 facilities reported two outbreaks and five facilities reported three outbreaks. 
Outbreak notification rate from elderly long-term care facilities, by region, France, November 2010-May 2012 (n=1,072 outbreaks)

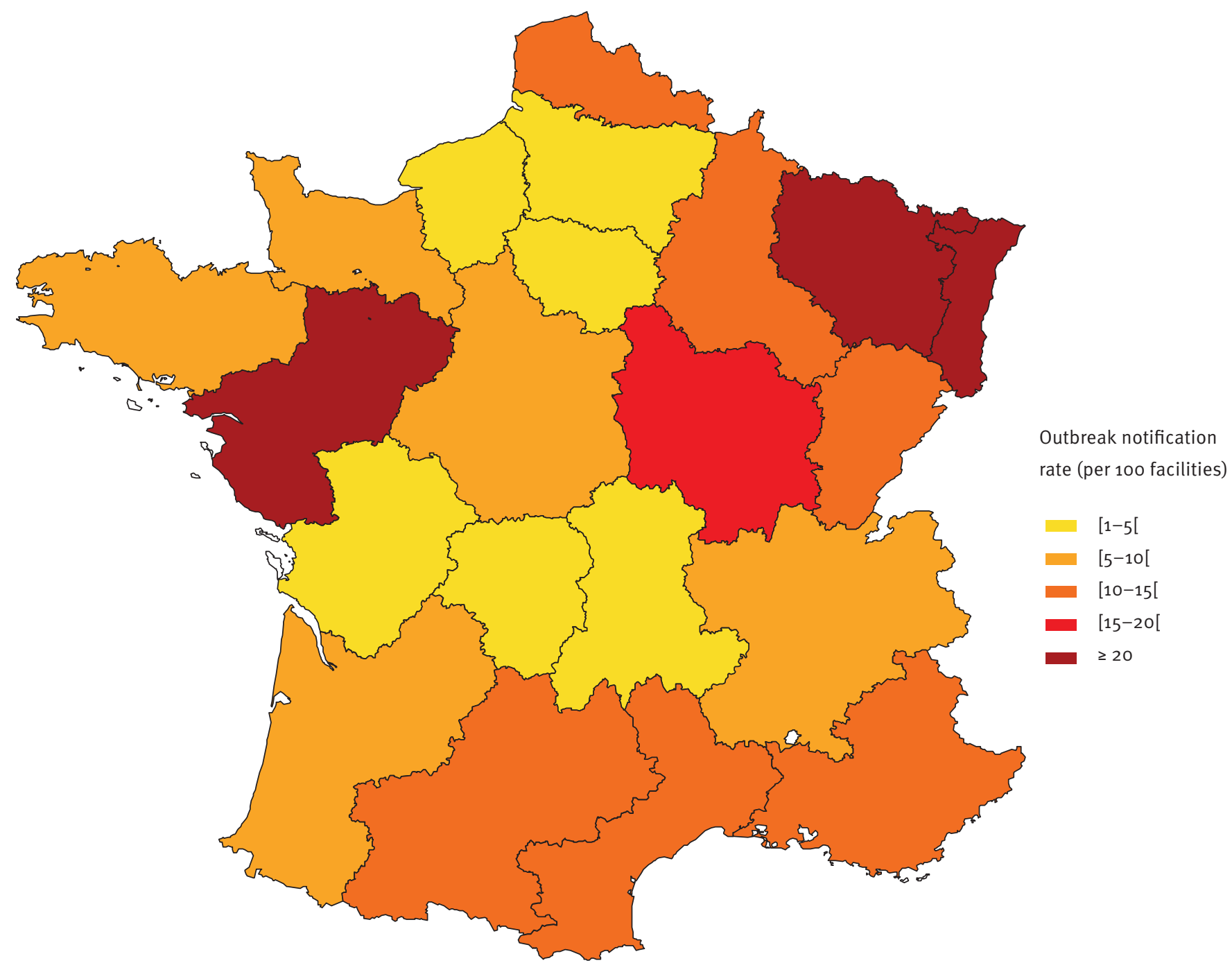

The outbreak notification rates were calculated over the 19 month study period so as to include two winter seasons.

The median number of residents in the facilities was 78 $(\mathrm{N}=999$ outbreaks; range: $12-545)$. The median number of staff members was 45 ( $\mathrm{N}=794$ outbreaks; range: 6-434). The median number of staff member per resident was 0.62 ( $N=793$ outbreaks; range: $0.08-2.5)$. The median level of dependence among residents was 700 $(\mathrm{N}=219$ outbreaks; range: 3-937). The median number of units in facilities was three ( $\mathrm{N}=715$ outbreaks; range: $1-12$ ).

\section{Outbreak reporting by place and time}

During the 2010/11 winter season, 442 facilities reported 473 outbreaks, giving an outbreak notification rate of 4.6 outbreaks per 100 facilities. During the 2011/12 winter season, 544 facilities reported 560 outbreaks, giving an outbreak notification rate of 5.5 outbreaks per 100 facilities. Over the 19 months study period, there was a great variation in the outbreak notification rate between regions, ranging from 2.7 outbreaks per 100 facilities in Picardie (in the Northern region) to 30.1 outbreaks per 100 facilities in Alsace (in the Eastern region) (Figure 1). As observed by the sentinel network for acute diarrhoeal disease in the general population, the distribution of gastroenteritis outbreaks in elderly LTCF by month followed a seasonal pattern with a peak during winter months (Figure 2). by month, France, November 2010-May $2012(n=1,072$ outbreaks)

\section{Characteristics of outbreaks}

The 1,072 outbreaks caused a total of 26,551 episodes of illness among residents, 5,548 episodes of illness among staff members, 227 transfers to acute care facilities and 60 deaths. Table 1 shows the characteristics of outbreaks. Of 1,025 outbreaks with available information, there were 899 outbreaks (88\%) with at least one staff member ill. 
Number of gastroenteritis outbreaks reported in elderly long-term care facilities and incidence rate of acute diarrhoeal disease in the general population ${ }^{a}$ by month, France, November 2010-May 2012 ( $\mathrm{n}=1,072$ outbreaks)

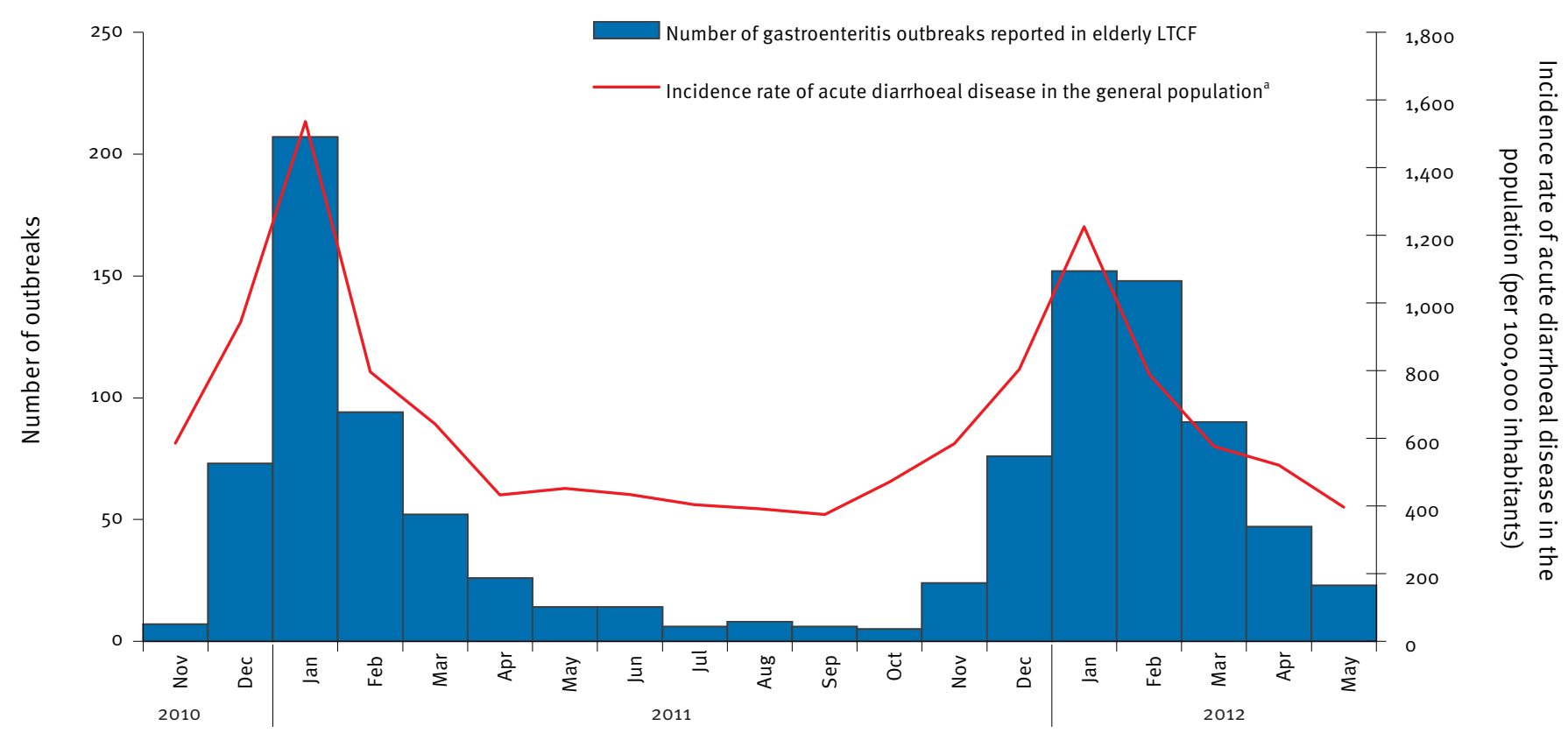

Month of notification

LTCF: long-term care facilities.

a Source of data on incidence of acute diarrhoeal disease: Réseau sentinelles, Institut national de la santé et de la recherche médicale (INSERM), Université Pierre et Marie Curie (UPMC) (http://www.sentiweb.fr).

\section{Mode of transmission}

Of 429 outbreaks (40\%) for which a suspected mode of transmission was specified, person-to-person accounted for 408 (95\%) outbreaks, foodborne for 10 ( $2 \%$ ) outbreaks, foodborne and person-to-person for six $(1 \%)$ outbreaks and waterborne for one $(\ll 1 \%)$ outbreak.

\section{Causative organisms}

Laboratory testing was performed in 603 (56\%) outbreaks and of these outbreaks, a pathogen was identified in 298 (49\%). Norovirus and rotavirus were the most frequent organisms (Table 2). Norovirus and/ or rotavirus were identified in 287 (96\%) outbreaks. Mixed pathogens were reported in 16 (5\%) outbreaks. of 774 outbreaks without confirmed aetiology (either no laboratory testing or negative laboratory test results), a hypothesis on the causative organism based on clinical or epidemiological information was reported in 182 (24\%) outbreaks. Of the latter 182 , a viral aetiology was suspected in 179 outbreaks (98\%).

Investigation and management of the outbreak The median delay in notifying the outbreak to health authorities was five days $(\mathrm{N}=1,062$ outbreaks; range: 0-94 days). An epidemiological investigation was conducted in $169(15.8 \%)$ of the total 1,072 outbreaks. It was a descriptive study in 126 outbreaks, a descriptive analysis of cases' food consumption in 22 outbreaks and an analytical study in 12 outbreaks.

Control measures were implemented in 1,054 (98\%) outbreaks. Of 928 outbreaks with available information, the median delay between the first case and implementation of control measures was one day (minimum: o; maximum: 34). In 799 (86\%) outbreaks, control measures were implemented within three days after the first case occurred. Considering the total 1,072 outbreaks, control measures put into effect included reinforcement of hand hygiene in 1,015 (95\%) outbreaks, contact precautions in 934 (87\%), cleaning or disinfection of the environment in 927 (86\%), restriction of patient movements in 904 (84\%), stopping or limitation of group activities in 617 (58\%) outbreaks, measures on food preparation/preservation/distribution in 468 (44\%) outbreaks. For the 899 outbreaks comprising at least one ill member of staff, exclusion of symptomatic staff was implemented in 578 (64\%).

For 197 (18\%) outbreaks, problems in the management of the outbreak were reported: understaffing in 107 (54\%) outbreaks, organisational problems in 88 (45\%) outbreaks, shortage of materials (e.g. gloves, singleuse clothing, etc.) in $23(12 \%)$ outbreaks, financial problems in $11(6 \%)$ outbreaks. 


\begin{tabular}{|c|c|c|c|c|}
\hline $\begin{array}{l}\text { Characteristics } \\
\text { ( } \mathrm{N}=\text { number of outbreaks with available information) }\end{array}$ & n (\%) & Mean & Median & Range \\
\hline Majority of cases $(\geq 50 \%)$ presenting with diarrhoea $(\mathrm{N}=981)$ & $934(95)$ & NA & NA & NA \\
\hline Majority of cases $(\geq 50 \%)$ presenting with vomiting $(\mathrm{N}=953)$ & $635(67)$ & NA & NA & NA \\
\hline Majority of cases $(\geq 50 \%)$ presenting with diarrhoea and vomiting $(\mathrm{N}=946)$ & $588(62)$ & NA & NA & NA \\
\hline Fever $\geq 38.5^{\circ} \mathrm{C}(\mathrm{N}=882)$ & $205(23)$ & NA & NA & NA \\
\hline Bloody diarrhoea $(\mathrm{N}=876)$ & $17(2)$ & NA & NA & NA \\
\hline Number of illnesses (residents and staff) $(\mathrm{N}=1,025)$ & NA & 30.1 & 26 & $5-140$ \\
\hline Attack rate among residents $(\%)(\mathrm{N}=998)$ & NA & 32.5 & 30.6 & $1.3-100$ \\
\hline Attack rate among staff members $(\%)(\mathrm{N}=786)$ & NA & 12.4 & 9.0 & $0-100$ \\
\hline Case fatality rate $(\%)(\mathrm{N}=965)$ & NA & 0.3 & o & $0-17^{\mathrm{a}}$ \\
\hline Mean duration of symptoms $(\mathrm{N}=800)$ & NA & 2.2 days & 2 days & 3 hours -9 days \\
\hline Duration of outbreak (days) $(\mathrm{N}=980)$ & NA & 10.1 & 9 & $0^{b}-57$ \\
\hline Proportion of affected units in facilities with at least 2 units $(\%)(\mathrm{N}=526)$ & NA & 82.2 & 100 & $1-100$ \\
\hline
\end{tabular}

NA: not applicable

a For three outbreaks the case fatality rate was $17 \%$. In these outbreaks six cases of illness including one death were reported among residents.

b Duration of outbreak: o day if the last case occurred the same day than the first case.

In 143 outbreaks ( $16 \%$ of 886 outbreaks with available information), facilities requested some advice from health authorities for the outbreak management and control.

\section{Factors associated with outbreaks characteristics}

Laboratory testing was significantly associated with the size of the facility and with the AR among residents. The proportion of outbreaks with laboratory testing increased together with the size of the facility (Table 3 , chi-squared test for trend $p$-value $=0.01$ ). The $A R$ among residents was greater in outbreaks with laboratory testing than without laboratory testing ( $A R=35 \%$ vs. $29 \%, p=0.0001)$. On the other hand, the AR among residents decreased as the size of the facility (characterised by the number of residents) increased (nonparametric test for trend $\mathrm{p}$-value<0.001).

The AR among residents and staff members were significantly different according to the aetiological agents identified in outbreaks, with highest AR observed in outbreaks due to norovirus or mixed pathogens (including norovirus). Longer duration of outbreaks was observed in outbreaks due to rotavirus or to mixed pathogens (including norovirus). The AR among residents and staff was lower and the duration of outbreaks was shorter when control measures were implemented within three days of date of symptom onset of the first case (Table 4 ). The case fatality rate (CFR) did not vary significantly according to these parameters.

There was no significant difference in the AR among residents according to the suspected mode of transmission $(p=0.61)$, type of setting $(p=0.35)$, mean level of dependence in the facility $(r=-0.01 ; p=0.79)$ or number of staff per residents $(r=0.04 ; p=0.16)$. The CFR did not vary significantly according to these parameters.

\section{Discussion}

This study shows that outbreaks of gastroenteritis in elderly LTCF cause substantial morbidity and mortality in France. The most frequent cause of gastroenteritis outbreaks in elderly LTCF is enteric viruses (and particularly norovirus) with spread from person to person, resulting in high AR among residents and staff members. These findings have been described in other countries [3,14-19].

\section{TABLE 2}

List of confirmed aetiological agents in outbreaks reported in elderly long-term care facilities, France, November 2010-May 2012 ( $n=298$ outbreaks)

\begin{tabular}{|l|c|} 
Aetiological agents & $\begin{array}{c}\text { Number of } \\
\text { outbreaks with } \\
\text { confirmed } \\
\text { aetiology }(\%)\end{array}$ \\
\hline Norovirus & $218(73)$ \\
\hline Rotavirus & $58(19)$ \\
\hline Norovirus and rotavirus & $11(4)$ \\
\hline Clostridium difficile & $4(1)$ \\
\hline Salmonella & $2(\ll 1)$ \\
\hline Norovirus and C. difficile & $2(\ll 1)$ \\
\hline Norovirus and Salmonella & $1(11)$ \\
\hline C. difficile and Campylobacter species & $1(11)$ \\
\hline Norovirus and rotavirus and C. difficile & $1(\ll 1)$ \\
\hline
\end{tabular}


TABLE 3

Characteristics of outbreaks in relation with the size of the elderly long-term care facility, France, November 2010May 2012

\begin{tabular}{|l|c|c|}
\hline $\begin{array}{l}\text { Size of the facility } \\
\text { (number of residents) }\end{array}$ & $\begin{array}{c}\text { Number of } \\
\text { outbreaks with } \\
\text { laboratory testing } \\
(\%)\end{array}$ & $\begin{array}{c}\text { Mean AR among } \\
\text { residents (\%) } \\
\text { (p25-p75) }\end{array}$ \\
\hline $0-49$ & $66(54)$ & $40.1(25 \cdot 5-55.5)$ \\
\hline $50-74$ & $175(58)$ & $33.6(18.5-46.5)$ \\
\hline $75-100$ & $194(59)$ & $32.5(19.1-44.9)$ \\
\hline $100-149$ & $82(63)$ & $27.8(14.5-37.3)$ \\
\hline$\geq 150$ & $46(74)$ & $19.1(7.9-24.8)$ \\
\hline
\end{tabular}

AR: attack rate; p25-p75: $25^{\text {th }}-75^{\text {th }}$ percentile.

Some of the results are subject to bias inherent to the voluntary and passive nature of the surveillance system. We observed a great variation in the outbreak notification rate between regions. Since the outbreak notification rate is not influenced by the disparity in the number of facilities in different regions, this variation probably reflects differences in investigation policies and reporting to health authorities. Indeed higher rates were observed in regions, which implemented specific studies or enhanced surveillance systems for outbreaks in elderly $\operatorname{LTCF}[20,21]$. The true burden of outbreaks in elderly LTCF is probably greatly underestimated, especially in regions, which had a low outbreak notification rate. It is also possible that large or more severe outbreaks were more frequently reported than others. However, if under-reporting is constant over time, trends can be monitored. In our study, the impact of the under-reporting bias seems to be stable over the entire study period since we observed the same seasonal pattern in the surveillance system for gastroenteritis outbreaks in elderly LTCF and in the surveillance of the incidence rate of acute diarrhoeal disease in the general population from the sentinel network from November 2010 to April 2012. The surveillance system for outbreaks in elderly LTCF could be an additional system (complementary to the existing one) to detect the beginning of seasonal gastroenteritis every year.

In France, outbreaks suspected to be linked to food (in any setting) are mandatory notifiable through a specific surveillance system for point source foodborne outbreaks. Data collected on foodborne outbreaks in LTCF through the mandatory system were not included in this study. Since outbreaks are not necessarily notified in both systems, we may have underestimated the frequency of foodborne outbreaks in elderly LTCF.

In approximately half of the outbreaks, laboratory testing had been performed to confirm the aetiological agent. The frequency of laboratory testing was associated with the size of the LTCF and with the AR among residents, with a greater proportion of laboratory testing in larger facilities and in outbreaks with a greater AR. It is important to continue to perform microbiological testing using standardised reference techniques on a substantial proportion of outbreaks in order to document the circulating strains/viruses and characterise them. However the microbiological investigation should not influence the outbreak management since the delay in getting the results can be long (and these sometimes become available when the outbreak is over). The outbreak control measures should be implemented as soon as possible based on the first clinical information and the suspected aetiological agent.

In half of outbreaks with laboratory testing, the aetiological agent was not reported, possibly because laboratory results were negative or because results were not updated in the database following reception of laboratory results.

Norovirus outbreaks in LTCF can be challenging to control because of the infectivity of the virus, the

TABLE 4

Comparison of attack rate and duration of outbreaks in elderly long-term care facilities according to aetiological agent and delay in implementing control measures, France, November 2010-May 2012

\begin{tabular}{|c|c|c|c|c|c|c|}
\hline Characteristics & $\begin{array}{l}\text { Median AR among } \\
\text { residents (\%) } \\
(\text { p25-p75) }\end{array}$ & $\begin{array}{c}\text { P-value } \\
\text { (Kruskal-Wallis) }\end{array}$ & $\begin{array}{c}\text { Median AR among } \\
\text { staff (\%) } \\
(\text { p25-p75) }\end{array}$ & $\begin{array}{c}\text { P-value } \\
\text { (Kruskal-Wallis) }\end{array}$ & $\begin{array}{c}\text { Median duration } \\
\text { of outbreaks in } \\
\text { days } \\
(\text { p25-p75) }\end{array}$ & $\begin{array}{c}\text { P-value } \\
\text { (Kruskal-Wallis) }\end{array}$ \\
\hline \multicolumn{7}{|l|}{ Pathogens } \\
\hline Norovirus & $38.2(24.1-50.0)$ & \multirow{5}{*}{0.004} & $11.6(5.9-24.1)$ & \multirow{5}{*}{0.0001} & $10(6-13)$ & \multirow{5}{*}{0.006} \\
\hline Rotavirus & $28.2(16.4-37.9)$ & & $3.8(2.1-9.8)$ & & $13(8-17)$ & \\
\hline Clostridium difficile & $32.5(18.8-44.2)$ & & $6.7(2.7-7.5)$ & & $10(8.5-15.5)$ & \\
\hline Salmonella & $18.6(5.7-31.5)$ & & $12.2(0-24.1)$ & & $4.5(3-6)$ & \\
\hline Mixed pathogens & $34.3(23.5-51.7)$ & & $18.1(1.4-26.0)$ & & $13(9.5-18.5)$ & \\
\hline \multicolumn{7}{|c|}{ Delay in implementing control measures after first case } \\
\hline Within 3 days & $30.3(17.0-45.3)$ & \multirow{2}{*}{0.002} & $8.6(3.6-16.7)$ & \multirow{2}{*}{0.002} & $8(5-12)$ & \multirow{2}{*}{0.0001} \\
\hline After 3 days & $35.0(24.4-46.3) ?$ & & $13.3(5.9-20.6)$ & & $12(8-17)$ & \\
\hline
\end{tabular}

AR: attack rate; p25-p75: 25th-75th percentile. 
environmental persistence and the possible long-term shedding by cases $[22,23]$. In our analysis, control measures had been implemented in a large proportion of outbreaks (98\%), suggesting that recommendations on managing gastrointestinal outbreaks in LTCF are well known and applied. However reported outbreaks are probably better managed and this proportion may not reflect the true knowledge and practices of LTCF when an outbreak occurs.

The efficacy of each specific control measure was not specifically studied but implementation of control measures tends to be associated with a lower AR and shorter duration of the outbreak when implemented within three days after the first case occurred This was also observed in a study of norovirus outbreaks in the Netherlands [24]. Of note, in our study, some control measures were less frequently implemented than others (e.g. exclusion of symptomatic staff members, limitation of group activities) although they can contribute to prevent transmission in outbreaks with person-toperson transmission [14]. Given the high proportion of outbreaks with at least one staff member ill (88\%) and their possible role in the transmission of infection to the residents, requiring that ,staff members temporarily stop from working while symptomatic is a relevant measure in outbreak management. The observation that this measure was implemented in only $64 \%$ of the outbreaks with at least one ill staff member raises concern. This may be due to difficulties encountered because of the resulting disorganisation of staff and services. It shows the need for contingency plans addressing these problems and identifying solutions for staff replacement.

The surveillance system for outbreaks of gastroenteritis in elderly LTCF provides valuable information to document the epidemiology of these outbreaks, to follow the evolution of associated morbidity and mortality and to assess the impact of national policies in order to guide public health actions. Data can also be used to estimate the implementation and effectiveness of recommended infection control measures.

Elderly LTCF are encouraged to continue to develop infection prevention and control plans and to notify any gastroenteritis outbreak to health authorities to ensure that they are rapidly controlled. Information on surveillance and notification should be largely distributed in order to increase participation in the system and improve the geographical representativeness of the surveillance data.

\section{Acknowledgement}

The authors would like to acknowledge: all LTCF which reported outbreaks; all Agences Régionales de Santé (ARS) and Cellules de l'InVS en région (Cire) for their participation in the surveillance system; the members of the steering committee of the surveillance scheme (Sophie Alsibai, Delphine Barataud, Pascal Chaud, Bruno Hubert, Caroline Six); Dieter Van Cauteren and Henriette de Valk for their valuable comments on the manuscript; the ARLIN/CCLIN network for their contribution in the prevention of infections in healthcare settings; Réseau Sentinelles for providing incidence data on acute diarrhoeal disease in France.

\section{Conflict of interest}

None declared.

\section{Authors' contributions}

All authors contributed to the interpretation of the results, the revision of the draft manuscript and approved the final version. Anne-Sophie Barret conducted the data analysis and wrote the manuscript; Nathalie Jourdan-Da Silva was involved in the design of the surveillance system for gastroenteritis outbreaks in elderly LTCF and in the data collection, study methods, data analysis; Katia Ambert-Balay was responsible for the viral laboratory analyses; Gilles Delmas was involved in the design of the surveillance system for gastroenteritis outbreaks in elderly LTCF and in defining the study methods; Angie Bone was involved in the data analysis; Jean-Michel Thiolet was involved in the design of the surveillance system for gastroenteritis outbreaks in elderly LTCF and in the data collection; Véronique Vaillant was involved in the design of the surveillance system for gastroenteritis outbreaks in elderly LTCF and in the data collection, study methods, and data analysis.

\section{References}

1. Garibaldi RA. Residential care and the elderly: the burden of infection. J Hosp Infect. 1999;43 Suppl:S9-18. http://dx.doi. org/10.1016/S0195-6701(99)90061-0

2. Strausbaugh LJ, Sukumar SR, Joseph CL. Infectious disease outbreaks in nursing homes: an unappreciated hazard for frail elderly persons. Clin Infect Dis. 2003;36(7):870-6. http:// dx.doi.org/10.1086/368197

3. Kirk MD, Veitch MG, Hall GV. Gastroenteritis and food-borne disease in elderly people living in long-term care. Clin Infect Dis. 2010;50(3):397-404. http://dx.doi.org/10.1086/649878

4. Carillo-Santisteve P, Ambert-Balay K, Arena C, Poujol I, Caillère N, Delmas G, et al. Epidémies hivernales de gastroentérites aiguës en France, bilan de trois saisons (2006/2007, 2007/2008 et 2008/2009). Bull Epidemiol Hebd. 2010;31:34951. French.

5. Ministère du travail, de l'emploi et de la santé, Direction Générale de la Santé. Ministères des solidarités et de la cohésion sociale. Circulaire interministérielle NDGCS/ DGS/2012/118 du 15 mars 2012 relative à la mise en oeuvre du programme national de prévention des infections dans le secteur médico-social 2011/2013; 11 Apr 2012.French.

6. Institut de veille sanitaire (InVs). Gastro-entérites aiguës virales. [Surveillance of acute gastroenteritis in France]. InVs; 2013. French. [Accessed 10 Jul 2014]. Available from: http://www.invs.sante.fr/Dossiersthematiques/Maladies-infectieuses/Risques-infectieuxd-origine-alimentaire/Gastro-enterites-aigues-virales/ Contexte-et-dispositif-de-surveillance

7. Flahault A, Blanchon T, Dorléans Y, Toubiana L, Vibert JF, Valleron AJ. Virtual surveillance of communicable diseases: a 20-year experience in France. Stat Methods Med Res. 2006;15(5):413-21.

8. Caillère N, Caserio-Schönemann C, Fournet N, Fouillet A, Pateron D, Leroy C, et al. Surveillance des urgences - Réseau OSCOUR® (Organisation de la surveillance coordonnée des urgences) - Résultats nationaux 2004/2011. 12 p. SaintMaurice: Institut de veille sanitaire; 2011. French.

9. Lyman WH, Walsh JF, Kotch JB, Weber DJ, Gunn E, Vinjé J. Prospective study of etiologic agents of acute gastroenteritis outbreaks in child care centers. J Pediatr. 2009;154(2):253-7. http://dx.doi.org/10.1016/j.jpeds.2008.07.057

10. Da Silva AK, Le Saux JC, Parnaudeau S, Pommepuy M, Elimelech M, Le Guyader FS. Evaluation of Removal of Noroviruses during Wastewater Treatment, Using Real-Time Reverse Transcription-PCR: Different Behaviors of Genogroups I and II. Appl Environ Microbiol. 2007;73(24):7891-7. http:// dx.doi.org/10.1128/AEM.01428-07 
11. Sdiri-Loulizi K, Gharbi-Khélifi H, de Rougemont A, Chouchane S, Sakly N, Ambert-Balay K, et al. Acute infantile gastroenteritis associated with human enteric viruses in Tunisia. J Clin Microbiol. 2008;46(4):1349-55. http://dx.doi. org/10.1128/JCM.02438-07

12. Direction de la recherche,des études, de l'évaluation et des statistiques (DREES). Les établissements d'hébergement pour personnes âgées. Activité, personnel et clientèle au 31 décembre 2007. Document de Travail.Paris: Ministère des Affaires sociales et de la Santé DREES; Feb 2010. French.

13. Benaim C, Froger J, Compan B, Pélissier J. [The assessment of autonomy in elderly people]. Ann Readapt Med Phys. 2005;48(6):336-40. French. http://dx.doi.org/10.1016/j. annrmp.2005.04.005

14. Greig JD, Lee MB. Enteric outbreaks in long-term care facilities and recommendations for prevention: a review. Epidemiol Infect. 2009;137(2):145-55. http://dx.doi.org/10.1017/ So950268808000757

15. Kirk MD, Fullerton KE, Hall GV, Gregory J, Stafford R, Veitch $M G$, et al. Surveillance for outbreaks of gastroenteritis in long-term care facilities, Australia, 2002-2008. Clin Infect Dis. 2010;51(8):907-14. http://dx.doi.org/10.1086/656406

16. Ryan MJ, Wall PG, Adak GK, Evans HS, Cowden JM. Outbreaks of infectious intestinal disease in residential institutions in England and Wales 1992-1994. J Infect. 1997;34(1):49-54. http://dx.doi.org/10.1016/S0163-4453(97)80009-6

17. Green KY, Belliot G, Taylor JL, Valdesuso J, Lew JF, Kapikian AZ, et al. A predominant role for Norwalk-like viruses as agents of epidemic gastroenteritis in Maryland nursing homes for the elderly. J Infect Dis. 2002;185(2):133-46. http://dx.doi. org/10.1086/338365

18. Van Duynhoven YT, de Jager CM, Kortbeek LM, Vennema H, Koopmans MP, van Leusden F, et al. A one-year intensified study of outbreaks of gastroenteritis in The Netherlands. Epidemiol Infect. 2005;133(1):9-21. http://dx.doi.org/10.1017/ So950268804002936

19. Rosenthal NA, Lee LE, Vermeulen BA, Hedberg K, Keene WE, Widdowson MA, et al. Epidemiological and genetic characteristics of norovirus outbreaks in long-term care facilities, 2003-2006. Epidemiol Infect. 2011;139(2):286-94. http://dx.doi.org/10.1017/S095026881000083X

20. Barataud D'Aury K, Leclère B, Hubert B. Surveillance des épidémies d'infections respiratoires aiguës et de gastroentérites aiguës dans les établissements d'hébergement pour personnes âgées dépendantes de la région des Pays de la Loire. Résultats de la surveillance au cours de l'hiver 20102011. Evaluation du dispositif de surveillance. Saint-Maurice: Institut de veille sanitaire; 2011. French.

21. Thouillot F, Delhostal C, Edel C, Bettinger A, Pothier P, Ambert-Balay K, et al. Gastroenteritis outbreaks in elderly homes in the east of France during winter 2009/10: aetiology research for a series of 37 outbreaks. Euro Surveill. 2012;17(9): $\mathrm{pii}=20103$.

22. Said MA, Perl TM, Sears CL. Healthcare epidemiology: gastrointestinal flu: norovirus in health care and long-term care facilities. Clin Infect Dis. 2008;47(9):1202-8. http:// dx.doi.org/10.1086/592299

23. Koopmans $M$. Noroviruses in healthcare settings: a challenging problem. J Hosp Infect. 2009;73(4):331-7. http://dx.doi. org/10.1016/j.jhin.2009.06.028

24. Friesema IH, Vennema H, Heijne JC, de Jager CM, Morroy G, van den Kerkhof JH, et al. Norovirus outbreaks in nursing homes: the evaluation of infection control measures. Epidemiol Infect. 2009;137(12):1722-33. http://dx.doi.org/10.1017/ So95026880900274X 